\title{
Peripheral and Central Target Requirements for Survival of Embryonic Rat Dorsal Root Ganglion Neurons in Slice Cultures
}

\author{
Richard Wetts and James E. Vaughn \\ Division of Neurosciences, Beckman Research Institute of the City of Hope, Duarte, California 91010
}

Developmental cell death in the nervous system usually is controlled by the availability of target-derived trophic factors. It is well established that dorsal root ganglia (DRG) neurons require the presence of their peripheral target for survival, but because of their central projections, it is possible that the spinal cord also may be required. Before examining this possibility in rat embryos, we first used terminal deoxynucleotidyl transferase-mediated biotinylated UTP nick end labeling (TUNEL) to determine that thoracic DRG cell death occurred from embryonic day 15 (E15) to E18. To determine the target requirements of DRG neurons, we used organotypic slice cultures of E15 thoracic trunk segments. After peripheral target removal, essentially all DRG neurons disappeared within $5 \mathrm{~d}$. In contrast, after removal of the spinal cord, approximately half of the DRG neurons survived for at least $8 \mathrm{~d}$. Hence, some E15
DRG neurons could survive without the spinal cord. However, those DRG neurons that died after spinal cord ablation apparently required trophic factors from both central and peripheral targets, because the presence of only one of these tissues was not adequate by itself to support this cell group. Addition of neurotrophin-3 (NT-3) to the culture medium rescued some DRG neurons after CNS removal, suggesting a possible role for NT-3 in vivo. In other experiments, cultures were established from older (E16) embryos, and essentially all neurons survived after spinal cord ablation, even without added factors. These and other experiments indicated that $\sim 65 \%$ of DRG neurons are transiently dependent on the CNS early in development.

Key words: apoptosis; NADPH-diaphorase histochemistry; nerve growth factor; neurotrophin-3; organotypic slice culture; sensory neurons; TUNEL histochemistry
Cell death plays a major role in sculpting the developing nervous system. Among vertebrates, this developmental event has been well studied in chick embryos (Oppenheim, 1991; Clarke and Oppenheim, 1995). For example, neurons in chick dorsal root ganglia (DRGs) die at a characteristic period in development, stage 25-38 (Hamburger and Levi-Montalcini, 1949; Carr and Simpson, 1978a; Hamburger et al., 1981). The DRG neurons that survive are clearly dependent on trophic factors produced by target tissues in the periphery, as demonstrated experimentally by the increased loss of neurons induced by the surgical removal of peripheral tissue (Hamburger and Levi-Montalcini, 1949; Carr and Simpson, 1978b; Hamburger and Yip, 1984; Riethmacher et al., 1997; Calderó et al., 1998). However, because DRG neurons have bifurcated processes that project to spinal cord as well as to peripheral tissues, it is possible that the CNS may provide another source of trophic support to developing DRG neurons. In other words, trophic factors produced by peripheral tissues could be sufficient for their survival, but an alternative possibility is that other trophic factors derived from the CNS might be required in addition to those produced peripherally.

Previous studies have reported conflicting results concerning the role of the CNS. Yip and Johnson (1984) found 50\% cell loss in DRGs after dorsal rhizotomy in newborn rats, suggesting a dependence on factors from the spinal cord. However, when Himes and Tessler (1989) repeated this experiment, they found

Received May 6, 1998; revised June 1, 1998; accepted June 10, 1998.

This research was supported by National Institute of Neurological Diseases and Stroke Grant NS25784. We thank Robert P. Barber, Lynn Brennan, Mariko Lee, and Christine Vaughn for their technical assistance.

Correspondence should be addressed to Dr. Richard Wetts, Division of Neurosciences, Sirbu Building, Beckman Research Institute of the City of Hope, 1450 East Duarte Road, Duarte, CA 91010-3011.

Copyright (C) 1998 Society for Neuroscience $\quad 0270-6474 / 98 / 186905-09 \$ 05.00 / 0$ no cell loss. In other experiments, degeneration of descending supraspinal projections by spinal cord transection induced an additional $30 \%$ cell loss after the period of naturally occurring cell death (Qin-Wei et al., 1994). Dissociated cell cultures and gene knock-out mutants established the trophic factor requirements for mammalian DRG neurons (Ruit et al., 1992; Snider, 1994; Snider and Wright, 1996), but because knock-outs eliminate expression from all tissues of the animal, this approach cannot reveal which tissues are required to provide these critical factors.

Before attempting to determine which tissues are required for the survival of embryonic rat DRG neurons, we first established the ages at which normal developmental cell death occurs in thoracic DRGs using terminal deoxynucleotidyl transferasemediated dUTP nick end labeling (TUNEL) (Gavrieli et al., 1992). Subsequently, we analyzed DRG neuron survival requirements by performing surgical perturbations of organotypic slice cultures. Surgical manipulation of mammalian embryos would be difficult, if not impossible, but organotypic slice cultures, which retain many normal cell-cell associations and target relationships, provide an experimentally accessible system that is less likely to induce artifacts than simple explant or dissociated cell cultures. Such slices of embryonic trunk contain the spinal cord, DRGs, and surrounding body wall tissue; in other words, they provide the DRG neurons with access to both peripheral and central target tissues. In addition, such preparations allowed us to remove either the body wall or the spinal cord microsurgically to determine whether both tissues are required for cell survival or whether only peripheral tissue regulates DRG cell death.

\section{MATERIALS AND METHODS}

Animal procedures and tissue preparation. Timed pregnancies were obtained by breeding Sprague Dawley rats (Charles River, Wilmington, MA) overnight, and if sperm were present in the vaginal smear the next 
morning, that day was designated as embryonic day 1 (E1). On E13-E21, pregnant females were deeply anesthetized with $3-5 \%$ halothane, administered with a precision vaporizer. The embryos were surgically removed from the uterus and were fixed either by immersion (E13-E16) or by transcardiac perfusion (E17-E21). Newborn rats [postnatal day 1 (P1)] were anesthetized with $18 \%$ chloral hydrate $(\sim 0.006 \mathrm{ml} / \mathrm{gm}$ body weight) before perfusion. For all ages, the fixative was either $4 \%$ paraformaldehyde or periodate-lysine and 2\% paraformaldehyde (McLean and Nakane, 1974) in 0.12 M Millonig's buffer, pH 7.4. After fixing overnight at $4^{\circ} \mathrm{C}$, blocks of upper thoracic (approximately $\mathrm{T} 1-\mathrm{T} 4$ ) spinal cord were rinsed in Millonig's buffer, cryoprotected in $30 \%$ sucrose, frozen on dry ice, and sectioned at $40 \mu \mathrm{m}$ in the transverse plane. The sections were collected free-floating in buffer, mounted on chrome alumcoated slides, and processed for TUNEL, followed by choline acetyltransferase (ChAT) immunocytochemistry.

TUNEL histochemistry. In accordance with the instructions accompanying the In Situ Cell Death Detection kit (Boehringer Mannheim, Indianapolis, IN), sections were first treated with $0.3 \% \mathrm{H}_{2} \mathrm{O}_{2}$ in methanol to suppress endogenous peroxidase activity. After rinses in Tris buffer ( $0.1 \mathrm{M}, \mathrm{pH} 7.4$, with $1.4 \% \mathrm{NaCl}$ and $0.1 \%$ bovine serum albumin) and pretreatment with $0.1 \%$ Triton $\mathrm{X}-100$, the sections were incubated in terminal deoxynucleotidyl transferase solution for $60 \mathrm{~min}$ at $37^{\circ} \mathrm{C}$. This solution included fluorescein-conjugated deoxyuridine triphosphate, which the transferase enzyme attaches to the free ends of any fragmented DNA. Next, the sections were washed in buffer and incubated in horseradish peroxidase-conjugated anti-fluorescein antibody for $30 \mathrm{~min}$ at $37^{\circ} \mathrm{C}$. After another rinse, the peroxidase was visualized by a $15 \mathrm{~min}$ treatment with $0.06 \% 3,3^{\prime}$-diaminobenzidine in Tris buffer with $0.007 \%$ $\mathrm{H}_{2} \mathrm{O}_{2}$ and $1 \% \mathrm{NiCl}_{2}$. Negative controls in which the terminal transferase enzyme was omitted were completely blank. Positive controls were created by pretreating the sections with $0.0001 \mathrm{gm} / \mathrm{ml}$ DNase I (in $0.1 \mathrm{M}$ Tris, $0.85 \% \mathrm{NaCl}, 7 \mathrm{~mm} \mathrm{MgCl}_{2}$, and $7 \mathrm{~mm} \beta$-mercaptoethanol) for 20 min at $37^{\circ} \mathrm{C}$. This pretreatment created DNA fragments in all nuclei, and the TUNEL in these healthy cells indicated that the terminal transferase and other reagents were able to penetrate the sections and label free DNA ends.

Slice culture preparation. In cold Gey's balanced salt solution, embryos were eviscerated, and the thoracic trunk was isolated and embedded in agarose (7.3\% of type IX; Sigma, St. Louis, MO). After hardening the agarose on ice, 250 - $\mu$ m-thick transverse slices were cut with a Campden Vibraslicer (Stoelting, Wood Dale, IL). Because a DRG extends over the entire length of each thoracic spinal segment $(\sim 350 \mu \mathrm{m}$ at E15; our unpublished observations), each $250 \mu \mathrm{m}$ slice had only a portion of a DRG on each side. Nonetheless, every slice had distinct DRGs present bilaterally, as confirmed visually using a dissecting microscope. Slices were picked up on a spatula, and control slices were placed directly onto coverslips coated with poly-D-lysine and dialyzed rat tail collagen. To prepare experimental slices, a freshly broken piece of razor blade was used to cut and remove tissue while the slice was still on the spatula. For "periphery-removed" experiments, an incision was made on each side at a $45^{\circ}$ angle, beginning just lateral to the DRGs and continuing through the centrum of the developing vertebra, thereby removing the body wall. For "CNS-ablated" experiments, the dorsal and ventral roots were transected bilaterally, and the spinal cord was excised. A single slice was placed onto each coverslip before transfer to a flat-bottom culture tube containing $0.5 \mathrm{ml}$ of EOL1 serum-free medium (Annis et al., 1990), supplemented in some experiments with $20 \mathrm{ng} / \mathrm{ml}$ of nerve growth factor (NGF) (Sigma) and in others with $5 \mathrm{ng} / \mathrm{ml}$ of neurotrophin-3 (NT-3) (Promega, Madison, WI). The culture tubes were sealed with gas permeable caps (Biomedical Polymers, Leominster, MA), placed into an incubator $\left(36^{\circ} \mathrm{C}, 5 \% \mathrm{CO}_{2}-95 \%\right.$ air $)$, and left stationary for $\sim 5 \mathrm{hr}$. After this attachment period, cultures were rotated in the incubator at 10 revolutions/hr, and the medium was changed every other day. At the end of the culture period, the medium was replaced with cold $4 \%$ paraformaldehyde for $2 \mathrm{hr}$ and then rinsed with Millonig's buffer. The fixed slices were infiltrated with graded sucrose to $20 \%$ followed by $7.5 \%$ gelatin in $20 \%$ sucrose, embedded in the gelatin-sucrose mixture, quick-frozen on dry ice, and sectioned at $40 \mu \mathrm{m}$. The sections were mounted on chrome alum-coated slides before staining with ChAT immunocytochemistry and diaphorase histochemistry, diaphorase histochemistry alone, or $0.5 \%$ cresyl echt violet in $50 \%$ ethanol.

ChAT immunocytochemistry. Sections were stained with ChAT immunocytochemistry to identify motor neurons for a separate study (Wetts and Vaughn, 1998). The immunocytochemistry protocol was identical to that described in Wetts and Vaughn (1996). With regard to the present work, ChAT immunocytochemistry resulted only in background labeling of DRG cells.

Diaphorase histochemistry. DRG neurons were identified by their NADPH-diaphorase histochemical reactivity, which is expressed in all DRG neurons during embryonic development (Wetts and Vaughn, 1993). Sections were pretreated with $1.0 \%$ Triton $\mathrm{X}-100$ in $0.1 \mathrm{M}$ Tris buffer for $15 \mathrm{~min}$. Staining was performed overnight at room temperature, usually using $0.075 \mathrm{mg} / \mathrm{ml} \beta$-NADPH, $0.03 \mathrm{mg} / \mathrm{ml}$ nitroblue tetrazolium, and $1.0 \%$ Triton X-100 in buffer (all reagents obtained from Sigma). The next morning, the tissue was rinsed six times with buffer, dehydrated using a graded acetone series, and coverslipped. No labeling occurred in control sections from which the NADPH was omitted.

Data collection. The numbers of TUNEL profiles were counted in each section of each DRG at $400 \times$ magnification. The profile counts at different ages were compared using Kruskal-Wallis one-way ANOVA, followed by Dunn's test (Instat software; GraphPad, San Diego, CA). In slice cultures, DRG neurons were identified using the criteria described in Results, and all neurons displaying a cell nucleus were counted in both ganglia in all sections of each culture. Neuron counts for different experimental conditions were compared using the Mann-Whitney $U$ test (Instat; GraphPad). Photomicrographs were taken with a Kodak DCS 420 digital camera mounted on a Leitz (Wetzlar, Germany) microscope, arranged and labeled with Adobe Photoshop software, and printed with a Codonics NP-1600 dye-sublimation printer at 300 pixels/inch.

\section{RESULTS}

\section{DRG cell death during embryonic development}

To determine the period of developmental cell death for rat DRG neurons, we labeled dying cells in sections of rat thoracic DRGs using TUNEL histochemistry. Labeled profiles were medium to small in size, round, and very dark (Fig. 1). Similar characteristics of TUNEL have been described previously (Migheli et al., 1994; Smale et al., 1995; Rossiter et al., 1996). Frequently observed were clusters of very small profiles, which possibly resulted after fragmentation of a single cell (Johnson and Deckwerth, 1993; McConkey and Orrenius, 1994). These morphological features, in addition to TUNEL itself, suggested that these cells were at relatively late stages of degeneration.

Few TUNEL-positive profiles were seen in E14 DRGs (Fig. $1 A$ ), but only $1 \mathrm{~d}$ later, numerous profiles were present (Fig. $1 B$ ). This dramatic TUNEL at E15 was greatly reduced as early as E16 (Fig. 1C). Profile counts confirmed the presence of a peak in TUNEL at E15 (Fig. 2). The number of TUNEL-positive profiles was very low on E13 and E14, increased suddenly at E15, decreased to an intermediate number of profiles for another 3-4 $\mathrm{d}$, and dropped to baseline levels by E21 and P1. This overall trend was significant $(p<0.0001)$, and further statistical tests indicated that TUNEL at E15-E18 was significantly higher than the labeling at other ages $(p<0.01)$. The low numbers of TUNEL-positive cells on E21 and P1 suggested that cell death among DRG neurons was essentially finished by birth, and little, if any, occurred postnatally, in agreement with previous reports (Scaravilli and Duchen, 1980; Hulsebosch et al., 1986).

\section{Peripheral target dependence of DRG neurons in slice cultures}

By E15, the beginning of the cell death period according to our TUNEL results, DRG neurons have processes entering the peripheral tissue, as well as some entering the spinal cord (Snider et al., 1992; Vaughn et al., 1992; Mirnics and Koerber, 1995) (Fig. 3). Thus, DRG neurons could have access to any trophic factors produced by either peripheral or CNS tissue. To test the putative support that each of these sources may provide to rat DRG neurons, we used an organotypic slice culture preparation (Robertson et al., 1989; Barber et al., 1993; Phelps et al., 1996). Control, "intact" cultures consisted of DRGs, spinal cord, and 

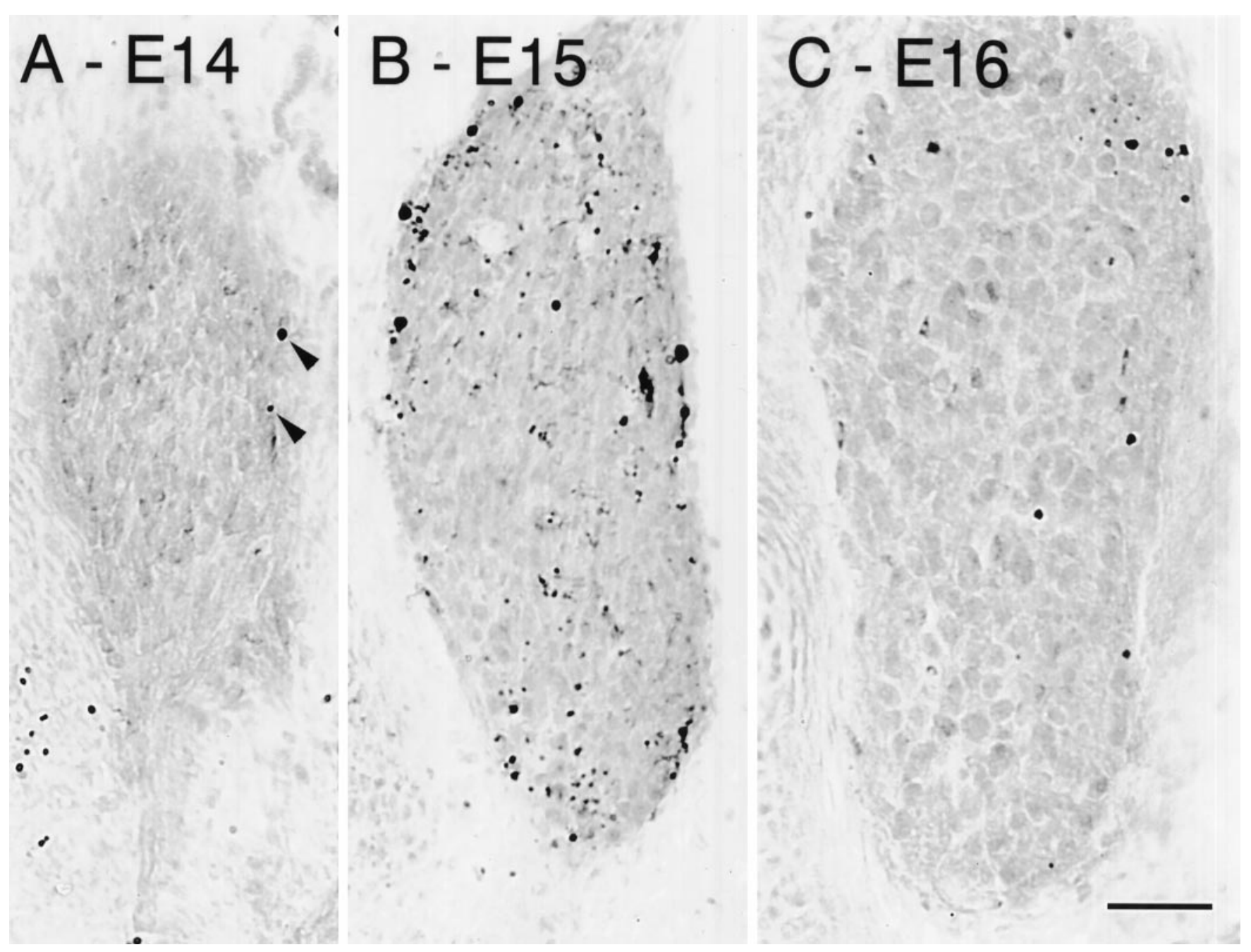

Figure 1. TUNEL-positive profiles in developing DRGs. TUNEL appears in these micrographs as black, small, mostly round profiles. A, At E14, very few TUNEL profiles were present (arrowheads). B, Only $1 \mathrm{~d}$ later at E15, many positive profiles were scattered throughout the DRGs. $C$, Beginning at E16, the labeling was greatly reduced compared with E15, but it was still noticeably more than on E14. Dorsal is top, and medial is right. Scale bar, $50 \mu \mathrm{m}$.

adjacent body wall taken from thoracic trunk segments of E15 rat embryos (Fig. 4A). At the end of the culture period, slices were fixed, sectioned, and stained with diaphorase histochemistry, combined in some cases with ChAT immunocytochemistry. DRG neurons were easily recognized by their round shape, relatively large size, position immediately lateral to the spinal cord, tendency to be clustered together, and diaphorase histochemical reactivity. The diaphorase histochemical marker appeared to be present in all DRG neurons at this developmental stage (Wetts and Vaughn, 1993) (Fig. 3). After as many as $15 \mathrm{~d}$ in vitro (DIV), the longest period examined, intact cultures still contained numerous diaphorase-positive DRG neurons (Fig. 4B), indicating that many DRG neurons survived without any growth factors added to the serum-free culture medium.

After removal of the peripheral tissue (Fig. 4C), DRG neurons were still present in most of these cultures after 3 DIV. However, after $4 \mathrm{~d}$, there was a substantial loss of diaphorase-positive DRG neurons. Most periphery-removed cultures had remnants of what used to be ganglia, but these structures contained few or no identifiable neurons (Fig. 4D). In 36 cultures analyzed 5-8 d after periphery removal, the average number of neurons remaining per slice was 47 , a number significantly ( $p<0.0001$ ) lower than the 372 neurons per slice present in intact cultures (Table 1). Similar to these results with diaphorase histochemistry, a more general stain, cresyl echt violet, also revealed the loss of essentially all large, lightly stained DRG cells from periphery-removed cultures (data not shown). Thus, nearly all DRG neurons disappeared from these cultures in the absence of their peripheral target tissue, although their central target was still present.

As a control for the effects of surgical trauma on cell viability, we prepared "incision-only" cultures in which cuts were made as in periphery-removed cultures, but no tissue was excised. After 5 DIV, axon bundles could be seen entering the peripheral tissue, suggesting that they had reestablished contact after the incision. In these cultures, the mean number of diaphorase-positive DRG neurons per slice was 301 , which was significantly $(p<0.0001)$ greater than the 47 per slice remaining in periphery-removed cultures but not significantly different from the 372 neurons per slice in intact cultures (Table 1). Thus, the survival of DRG neurons in these incision-only cultures indicated that axon injury alone was not sufficient for the disappearance of these neurons; instead, actual removal of the peripheral tissue was required. 


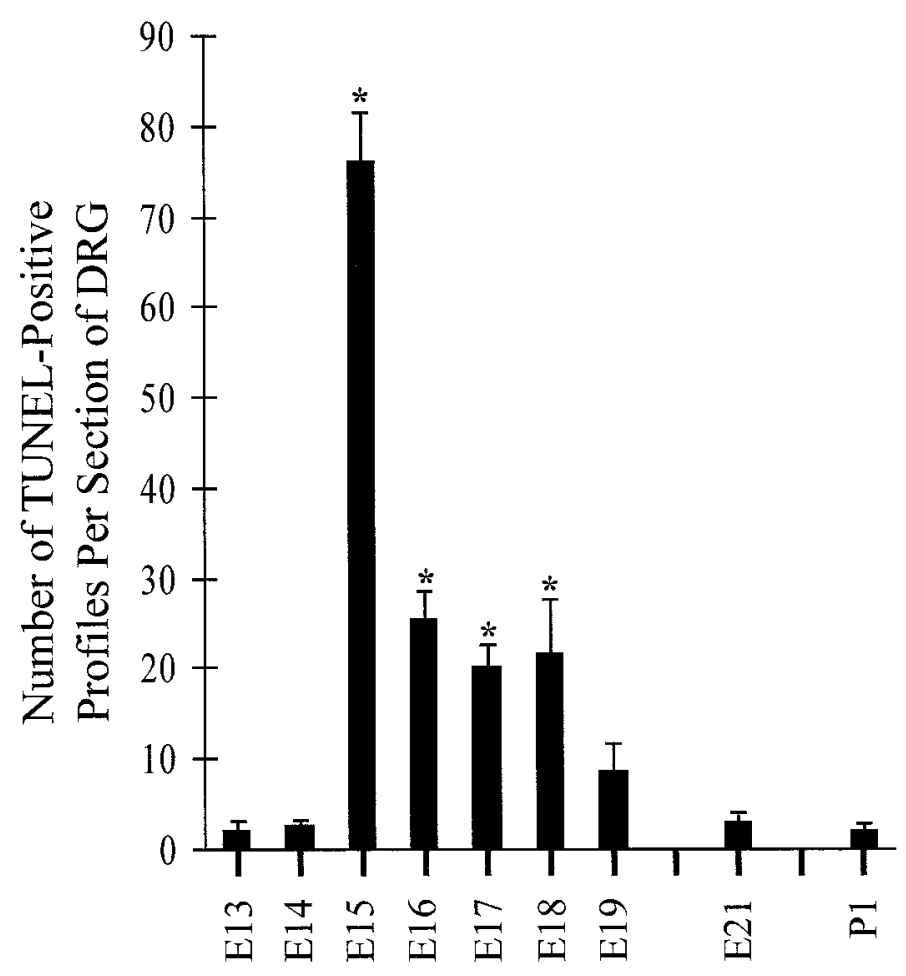

Age

Figure 2. Mean number of TUNEL-positive profiles per section of DRG at various ages. The height of each bar represents the mean value for one to four animals at each age analyzed (no animals were examined on E20 or E22). Error bars indicate SEM. There were statistically significant differences among these ages $(p<0.0001$, Kruskal-Wallis test). Specifically, the ages marked with asterisks had significantly greater numbers of TUNEL profiles than the other ages $(p<0.01)$.

\section{Rescue of DRG neurons in periphery-removed cultures with NGF}

To determine whether DRG neurons had died after periphery removal or had simply lost their staining, we tried to rescue them with NGF, a trophic factor for DRG neurons (Hamburger and Yip, 1984; Ruit et al., 1992; Snider, 1994). In "NGFsupplemented" cultures, peripheral tissue was removed (Fig. 4C), and NGF was added to the medium for the entire culture period. DRG neurons in these cultures not only survived (Fig. $5 \mathrm{~A}$ ) but were considerably more numerous than in intact cultures (Table 1 ). We then prepared "delayed-NGF" cultures; after periphery removal, these slices were grown for $\geq 3 \mathrm{~d}$ in serum-free medium, allowing the DRG neurons time to react to peripheral target deprivation. After this initial factor-free period, NGF was added for another $4-5 \mathrm{~d}$ to rescue any neurons that might have lost diaphorase historeactivity but were still present and viable. Such a rescue occurred in cultures deprived of NGF for only $3 \mathrm{~d}$; all of these cultures had conspicuous numbers of DRG neurons present. After 4-5 d of deprivation, however, very few diaphorase-positive neurons could be rescued (Fig. 5B). The mean number per slice (80) was similar to the number remaining in periphery-removed cultures without any NGF (47) and, more importantly, was significantly $(p<0.0001)$ less than the number in intact cultures (372). Because they could not be rescued by NGF, we concluded that all but a fraction of the DRG neurons died after $4 \mathrm{~d}$ without their peripheral target. Thus, these exper-

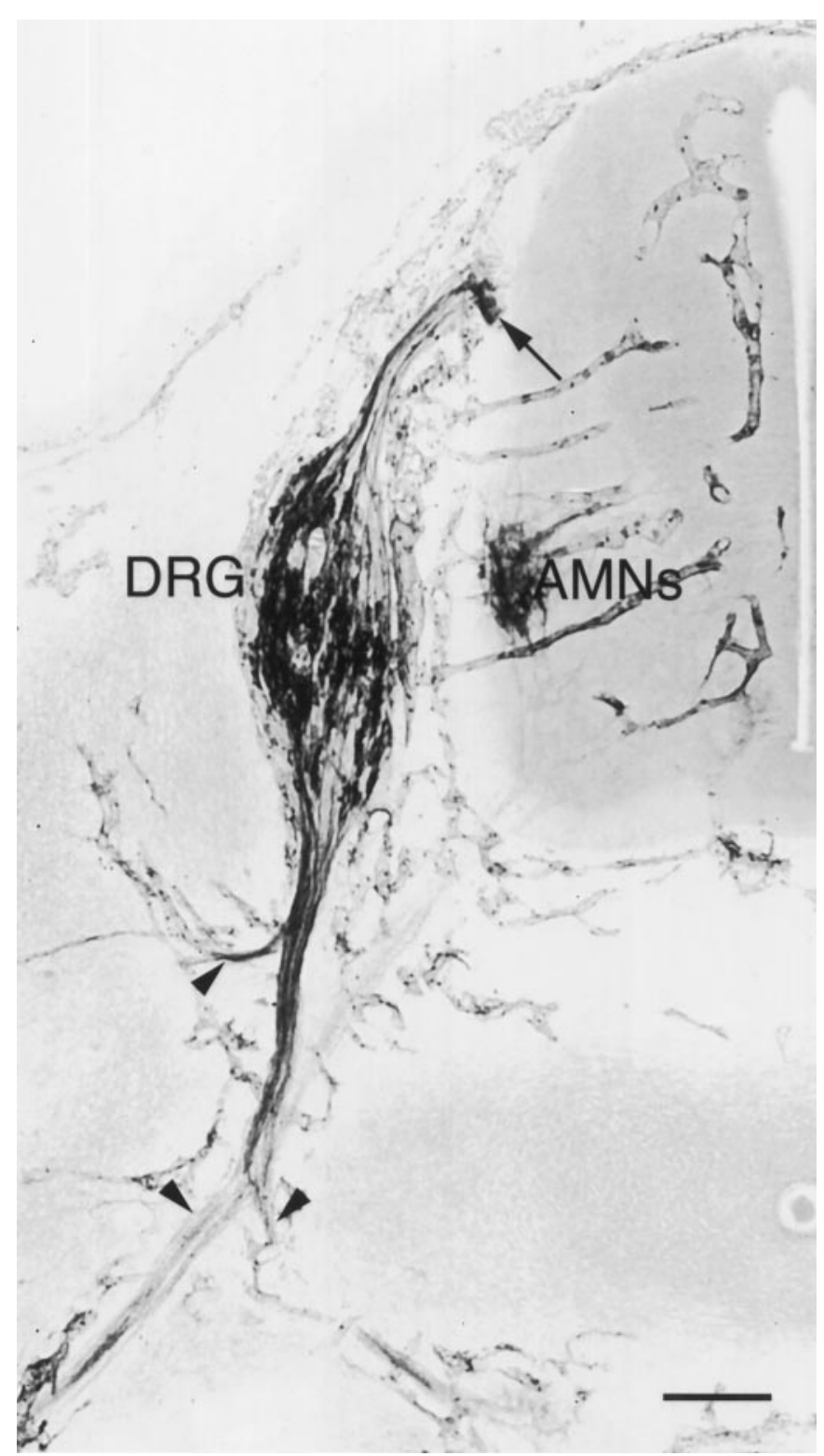

Figure 3. E15 rat thoracic spinal cord and DRG, stained with diaphorase histochemistry. This developmental stage represents the time of peak TUNEL in the DRG and the age at which slice culture experiments were initiated. At this age, all DRG neurons appeared to be diaphorasepositive (Wetts and Vaughn, 1993). Their central processes were visible extending into the dorsolateral funiculus of the spinal cord (arrow), and the peripheral processes were visible branching in the peripheral target tissue (arrowheads). The autonomic motor neurons (AMNs) (Wetts et al., 1995) also were diaphorase-positive, as were the endothelial cells of blood vessels. Scale bar, $100 \mu \mathrm{m}$.

iments demonstrated the importance of peripheral tissue in supporting the survival of rat DRG neurons.

\section{Central target relationships of DRG neurons in slice cultures}

We next performed experiments to test the role of central targets on DRG neuron viability. To prepare CNS-ablated cultures, the spinal cord was excised from fresh slices, leaving the DRGs and their peripheral target tissues in place (Fig. 6A). After 5-8 DIV in factor-free culture medium, many diaphorase-positive DRG neurons were present in these cultures (Fig. 6B). Clearly, some 

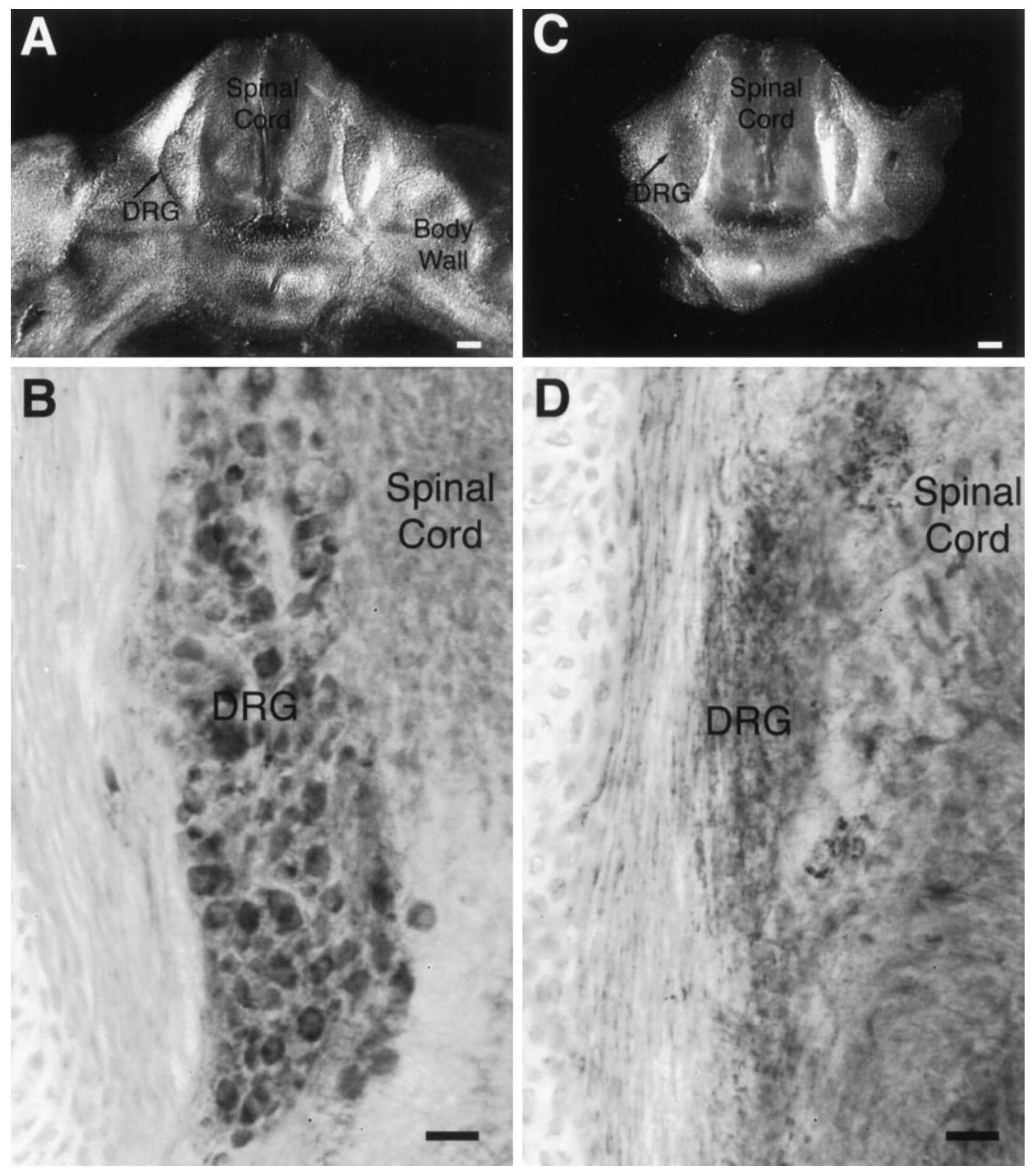

Figure 4. Peripheral target dependency of DRG neurons in organotypic slice cultures of E15 thoracic trunk. $A$, A freshly prepared transverse slice consisted of the spinal cord, DRGs, and adjacent peripheral tissues such as the body wall. $B$, After $5 \mathrm{~d}$ of culture in serum-free medium, slices were fixed, sectioned, and processed for combined ChAT immunocytochemistry and diaphorase histochemistry. Numerous diaphorase-positive DRG neurons were clearly visible in these intact cultures (neuron counts are presented in Table 1). $C$, For periphery-removed cultures, most of the peripheral tissue was surgically removed at the beginning of the culture period. $D$, After $5 \mathrm{~d}$ without peripheral tissue and without added growth factors, only a small remnant of the DRG is visible. No surviving cells can be discerned in this section, a result that occurred in most sections of periphery-removed cultures. Dorsal is top $(A-D)$, and medial is right $(B, D)$. Scale bars: $A, C, 100 \mu \mathrm{m} ; B, D, 20 \mu \mathrm{m}$.

rat DRG neurons did not require trophic factors derived from the spinal cord for their survival in vitro. Cell counts, however, revealed that the mean number of neurons remaining was 182 cells per slice (Table 1$)$, a number significantly $(p<0.0001)$ less than that in intact cultures (372). Thus, approximately half of the
E15 DRG neurons appeared to require the CNS for their survival in vitro.

As a control for surgical trauma in the CNS-ablated cultures, "sham-ablated" cultures were prepared by making incisions through the dorsal roots, but the spinal cord was left in place. As 


\begin{tabular}{lc}
\hline $\begin{array}{l}\text { Table 1. Mean number of diaphorase-positive DRG neurons present } \\
\text { per thoracic slice prepared from E15 rat embryos and cultured for } \\
\text { 5-8 } \mathbf{d} \text { in vitro }\end{array}$ \\
$\begin{array}{lc}\text { Number of DRG } \\
\text { neurons [Mean } \pm \text { SEM } \\
\text { (number of cultures)] }\end{array}$ \\
Experimental treatment & $372 \pm 39(40)$ \\
\hline Intact (controls) & $301 \pm 71(11)^{a}$ \\
Incision only (sham periphery removed) & $47 \pm 10(36)^{b}$ \\
Periphery removed & $1278 \pm 303(9)$ \\
Continuous NGF after periphery removed & $80 \pm 8(19)^{c}$ \\
NGF started 4-5 d after periphery removed & $337 \pm 62(20)^{a}$ \\
Sham CNS ablated & $182 \pm 18(55)^{d}$ \\
CNS ablated & $254 \pm 25(36)^{e}$ \\
CNS ablated + NT-3 &
\end{tabular}

${ }^{a}$ Not significantly different from intact group (Mann-Whitney $U$ test).

${ }^{b}$ Significantly different from both intact $(p<0.00001)$ and periphery incision only $(p<0.0001)$ groups.

${ }^{c}$ Significantly different from periphery-removed group $(p=0.0006)$.

${ }^{d}$ Significantly different from sham CNS-ablated group $(p=0.026)$.

${ }^{e}$ Significantly different from CNS-ablated group $(p=0.018)$.

early as 3 DIV, DRG neuronal processes, labeled with the specific marker TAG-1 (Vaughn et al., 1992), had reentered the spinal cord (data not shown), thereby potentially regaining access to centrally derived trophic factors. At 5-7 d, the mean number of DRG neurons in these sham-ablated cultures was 337 per slice. Because this value is similar to the mean number in intact cultures (372), we concluded that severing the dorsal processes did not reduce the viability of DRG neurons. However, the mean number of DRG neurons remaining after CNS removal (182) was significantly $(p<0.05)$ lower than in sham-ablated cultures (337). Thus, approximately half of the neurons disappeared because of the absence of the CNS, although the peripheral tissue was still present. This result suggested that some E15 DRG neurons required the presence of both central and peripheral target tissue for their survival.

In addition to the cultures made from E15 embryos, we also prepared slices from E14 and E16 embryos (Table 2). In E14derived cultures, the CNS-ablated slices had only $37 \%$ as many DRG neurons as intact slices. This percentage is distinctly lower than the $49 \%$ that survived without the spinal cord in E15 cultures. In contrast, as many as $86 \%$ of the DRG neurons survived after CNS ablation in E16 derived slices. This percentage was not statistically different from $100 \%$, indicating that by E16, practically all of the DRG neurons could survive in culture without the presence of the spinal cord. The age-related increase in the percentage of surviving DRG neurons indicated that their dependence on the CNS was transient.

\section{Rescue of DRG neurons in CNS-ablated cultures with NT-3}

Based on the results described above, NT-3 appeared as a likely candidate to be a CNS-derived survival factor for developing DRG neurons (see Discussion for details). To test this hypothesis, NT-3 was added to the culture medium of slices derived from E15 embryos. With NT-3 added for the first $2 \mathrm{~d}$ of the culture period (Table 1), the mean number of diaphorase-positive DRG neurons per CNS-ablated slice (254) was significantly $(p<0.02)$ greater than the number per untreated CNS-ablated slice (182). Thus, added NT-3 was able to support DRG neurons after removal of the spinal cord. The maximum number of DRG neurons was rescued with $5 \mathrm{ng} / \mathrm{ml} \mathrm{NT-3}$ added for only the first
$2 \mathrm{~d}$ of the culture period. The presence of NT-3 for the entire culture period did not rescue any additional cells compared with the $2 \mathrm{~d}$ treatment (data not shown), as expected considering the transient nature of their CNS dependence. Furthermore, $5 \mathrm{ng} / \mathrm{ml}$ NT-3 was sufficient, because higher doses did not rescue any additional cells, and $1 \mathrm{ng} / \mathrm{ml}$ did not rescue as many DRG neurons after removal of the spinal cord.

\section{DISCUSSION \\ Cell death in developing DRGs in vivo}

To determine the period of cell death in rat thoracic DRGs, we labeled dying cells using the TUNEL histochemical procedure. Significant levels of labeling occurred on E15-E18, whereas much lower numbers of labeled profiles were present at the other ages examined. Because developmental cell death is generally characterized by its occurrence during a particular period of time, we interpret the high level of labeling (E15-E18) as indicating the period of specific developmental cell death of DRG neurons. This period of cell death in thoracic DRGs (present results) occurs somewhat earlier than in lumbar DRGs (Coggeshall et al., 1994). This timing in rat DRGs is similar to the timing of cell death in chick DRGs, which occurs later in ganglia that innervate the limbs (brachial and lumbar) than in nonlimb ganglia (Hamburger et al., 1981). If TUNEL on E15-E18 indicates the period of developmental cell death of the DRG neurons, then the low level of labeling on the other ages might be some type of random cell death of either neurons or even glial cells. The advanced stage of degeneration of the TUNEL-positive profiles makes it difficult, if not impossible, to identify the cell type either morphologically or immunocytochemically.

In most neuronal populations that undergo developmental cell death, cell generation finishes several days before the neurons begin to die (Clarke and Oppenheim, 1995; Burek and Oppenheim, 1996). During this period before cell death begins, motor neurons, for example, send axons to their postsynaptic target and form synapses (Landmesser and Pilar, 1976; Chu-Wang and Oppenheim, 1978), providing the cells an opportunity to obtain trophic factors. DRG neurons, however, do not follow this pattern; in their case, the period of cell death begins before the last birth dates are complete. In chicks, for example, brachial DRG neuronal birth dates occur at E4.5-E7 (Carr and Simpson, 1978a), and cell death occurs during an overlapping period, E5.5-E12 (Carr and Simpson, 1978a; Hamburger et al., 1981). Some DRG neurons become pyknotic and degenerate within $2 \mathrm{hr}$ of tritiated thymidine labeling (Carr and Simpson, 1982). As a consequence of early cell death, these neurons die before their axons can reach the periphery (Hamburger et al., 1981). Similar events probably occur in rodent DRGs, because cell death begins on E15 in rats (present results) and at equivalent ages in the mouse (Migheli et al., 1994; ElShamy and Ernfors, 1996; White et al., 1998) before the generation of neurons is complete (E12-E16) (Lawson et al., 1974; Sims and Vaughn, 1979; Kitao et al., 1996). Because early dying cells do not have the opportunity to obtain trophic factors from their peripheral targets, it has been suggested that factors derived from their central targets may be important in regulating this early cell death (Scaravilli and Duchen, 1980; Carr and Simpson, 1982; Coggeshall et al., 1994). Hence, it was necessary to determine experimentally whether the CNS contributes to the survival of DRG neurons. 

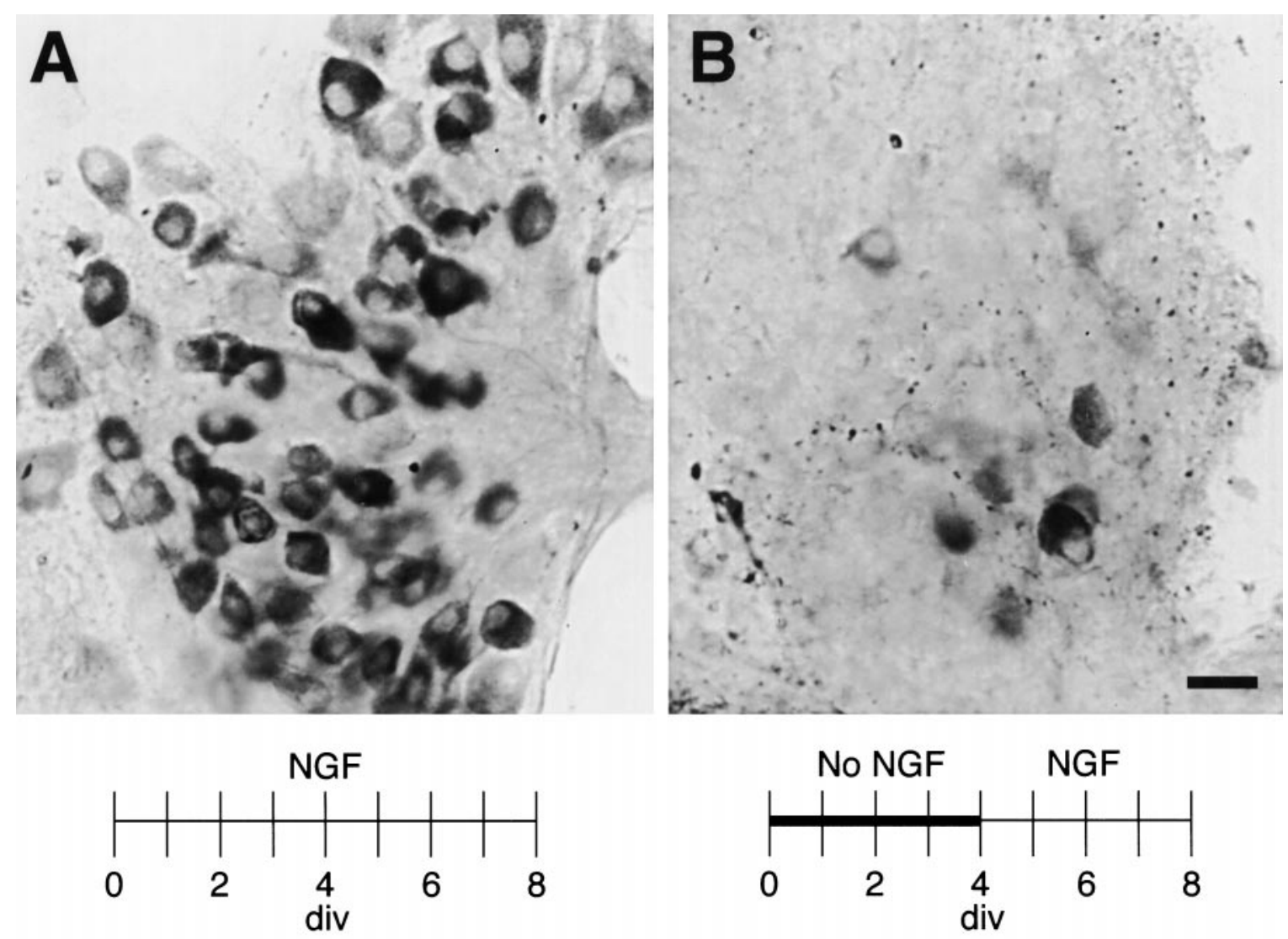

Figure 5. Rescue of periphery-deprived DRG neurons by NGF treatment. $A$, After removal of the peripheral tissue (as in Fig. 4C) and NGF treatment for the entire $8 \mathrm{DIV}$, many diaphorase-positive neurons were present (Table 1). These results confirm that NGF can prevent the death of DRG neurons, even in the absence of peripheral tissues. $B$, Delayed-NGF cultures were maintained in factor-free medium for the first $4 \mathrm{~d}$ after periphery removal, and then the medium was supplemented with NGF for the last $4 \mathrm{~d}$. Only a few DRG neurons were present in these cultures (Table 1), indicating that most DRG neurons were dead after $4 \mathrm{~d}$ of peripheral target deprivation. In the time lines below each micrograph, the thin line indicates the days with NGF present, and the thick line indicates the days without NGF. Dorsal is top, and medial is left. Scale bar, $20 \mu \mathrm{m}$.

\section{Peripheral target dependence in vitro}

To determine which tissues provide trophic support to rat DRG neurons, our experimental approach was to use organotypic slice cultures. These cultures were maintained in a serum-free medium that contained no known trophic factors, so that the survival of DRG neurons was dependent solely on other tissues in the slice. To verify this, we removed all of the peripheral tissues except for some cartilage of the developing vertebra, expecting DRG neurons to die, because this is the result after periphery removal in chick embryos (Hamburger and Levi-Montalcini, 1949; Hamburger et al., 1981; Hamburger and Yip, 1984). Indeed, removal of peripheral tissues greatly reduced the number of diaphorasepositive neurons (Table 1). Because it is conceivable that target deprivation caused only a downregulation of a marker such as diaphorase activity, we also used the general stain cresyl echt violet and again found few or no neurons remaining after periphery removal. As a third approach, we tried to rescue the DRG neurons by adding NGF to the culture medium $4 \mathrm{~d}$ after periphery removal. Only a small number of neurons were still viable and able to respond to the NGF treatment. This number (80) was somewhat greater than the mean number of neurons seen per slice without NGF treatment (47), probably because the NGF would have made these neurons healthier and hence easier to detect. Both numbers were significantly smaller than the mean number in intact cultures (372), supporting our conclusion that peripheral tissue is required for the survival of these E15 DRG neurons.
More neurons were present in the NGF-supplemented cultures than were present in the intact cultures, suggesting that some loss of cells occurred in the control cultures. This was not surprising considering that developmental cell death takes place normally at E15 in vivo, as illustrated by our TUNEL results. Furthermore, it is likely that a portion of the periphery was removed unavoidably in the process of making slices for culture, thereby inducing the loss of additional neurons. Nonetheless, an average of 372 DRG neurons per slice survived in control cultures. Hence, this is the critical number for comparison to the number of neurons remaining after tissue removal.

\section{Transient CNS dependence in vitro}

Although essentially all DRG neurons depended on the presence of peripheral tissue, two-thirds of the neurons in E14 cultures and one-half of those in E15 cultures also required the presence of the CNS for their survival. Hence, these neurons depended on trophic factors from both central and peripheral targets. The factors supplied by only the periphery or only the spinal cord were inadequate by themselves for the viability of this group of DRG neurons that died after spinal cord removal at E14 and E15.

There were three reasons for considering NT-3 as possibly being a CNS-derived survival factor. First, one site of NT-3 production is the spinal cord (Ernfors and Persson, 1991; Schecterson and Bothwell, 1992; Fariñas et al., 1996). Second, our results with CNS-ablated cultures from different embryonic ages 

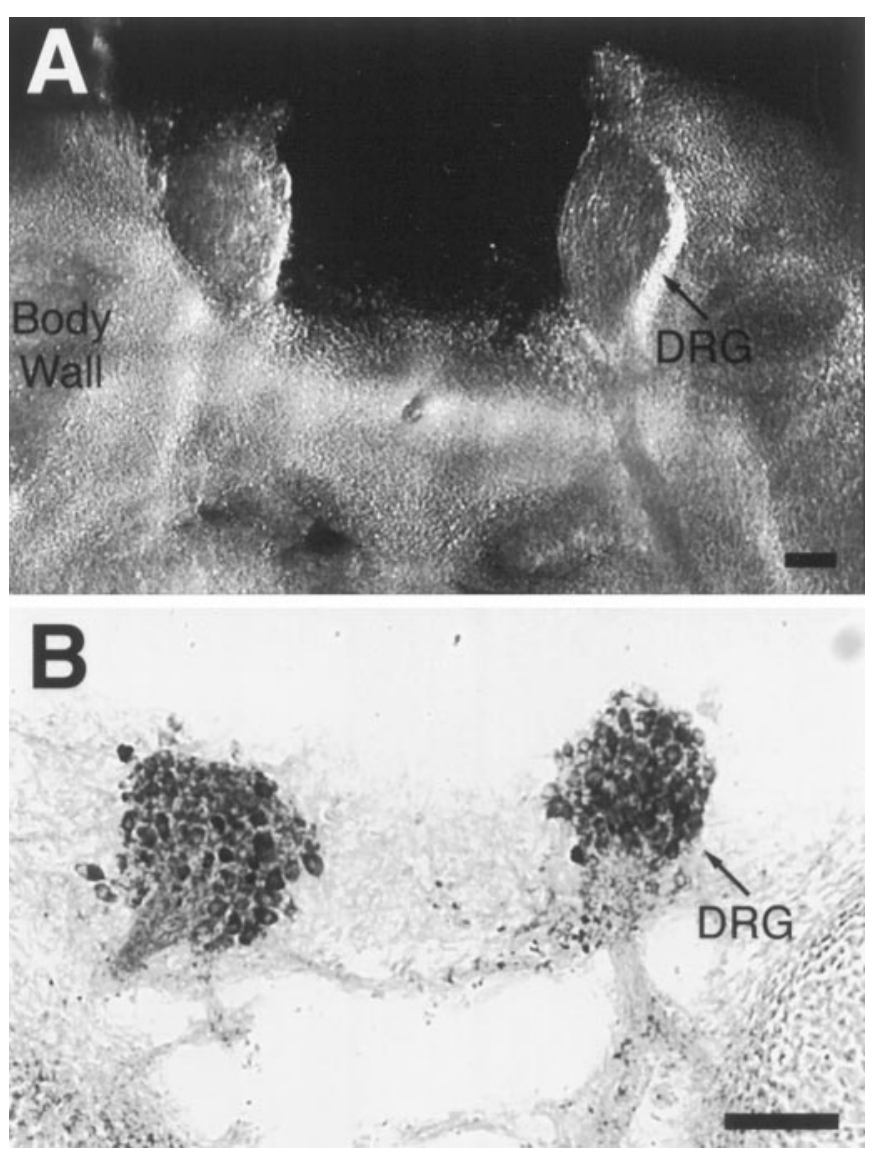

Figure 6. Independence of some DRG neurons from their central target tissue. $A$, A CNS-ablated culture was prepared by excising the spinal cord from a freshly prepared E15 slice. $B$, After $8 \mathrm{~d}$ in vitro, many diaphorasepositive DRG neurons were clearly present in such CNS-ablated cultures, indicating that some DRG neurons survived in the absence of the spinal cord. Quantitative data are presented in Tables 1 and 2. Dorsal is top. Scale bar, $100 \mu \mathrm{m}$.

\begin{tabular}{lll}
\hline $\begin{array}{l}\text { Table 2. Mean number of diaphorase-positive DRG neurons present } \\
\text { per cultured slice }\end{array}$ & \\
$\begin{array}{l}\text { Age and experimental } \\
\text { treatment }\end{array}$ & $\begin{array}{l}\text { Number of DRG neurons } \\
\text { [Mean } \pm \text { SEM } \\
\text { (number of cultures) }\end{array}$ & $\begin{array}{l}\text { Percent of } \\
\text { intact }\end{array}$ \\
\hline E14 intact & $622 \pm 85(15)$ & \\
E14 CNS ablated & $232 \pm 32(17)^{a}$ & 37 \\
E15 intact & $372 \pm 39(40)$ & \\
E15 CNS ablated & $182 \pm 18(55)^{b}$ & 49 \\
E16 intact & $310 \pm 27(24)$ & 86 \\
E16 CNS ablated & $267 \pm 49(18)^{c}$ & \\
\hline
\end{tabular}

${ }^{a}$ Significantly different from E14 intact group $(p<0.002)$.

${ }^{b}$ Significantly different from E15 intact group $(p<0.001)$.

${ }^{c}$ Not significantly different from E16 intact group $(p>0.05)$

(Table 2) demonstrated that the dependence on the CNS was early and transient, and it is known that the DRG neuronal dependence on NT-3 is early and transient (White et al., 1996; Liebl et al., 1997). Developing DRG neurons first express TrkC (the receptor for NT-3), and later they downregulate TrkC and upregulate TrkA as they lose their dependence on NT-3 and become dependent on NGF for survival (White et al., 1996). Third, in NT-3 knock-out mutant mice, only $\sim 30-50 \%$ of DRG neurons survive (Ernfors et al., 1994; Fariñas et al., 1994; Tessarollo et al., 1994), similar to the $37 \%$ remaining in our E14 CNS-ablated cultures. This extensive loss of DRG neurons in the mutants encompasses sensory neurons in addition to the subpopulation of muscle spindle afferents that specifically require NT-3 later in development (Oakley et al., 1997). Furthermore, these transiently NT-3-dependent neurons have been shown to require a source of NT-3 other than muscle spindles (Wright et al., 1997). It is currently thought that DRG neurons obtain NT-3 from the tissues surrounding the DRG (Fariñas et al., 1996) and possibly in an autocrine manner from the DRG itself (Schecterson and Bothwell, 1992; Snider, 1994; ElShamy and Ernfors, 1996). Our data suggest that DRG neurons might require NT-3 from the CNS in addition to these peripheral sources.

If the CNS-derived factor is NT-3, it is unclear exactly how this factor reaches the DRG neurons. The central processes of DRG neurons extend only into the marginal zone at E15 (Snider et al., 1992; Vaughn et al., 1992; Mirnics and Koerber, 1995; Ozaki and Snider, 1997) (Fig. 3). Hence, these processes do not yet have direct contact with their target cells, especially the NT-3producing somatic motor neurons in the ventral horn. This observation suggests that NT-3 might have to diff use some distance from the site of production, either much of the dorsoventral height of the spinal cord or out of the CNS and directly into the adjacent ganglion. This apparently long diffusion distance of CNS-derived NT-3 would be unusual compared with factors that typically are available only to processes that have formed synaptic contacts (Oppenheim, 1991; Burek and Oppenheim, 1996).

Regardless of the identity of the CNS-derived trophic factor, it is unclear why intact cultures from embryos of different ages have different numbers of DRG neurons (Table 2). One possibility is that because more peripheral tissue seems to be present after preparing slices from younger embryos, more DRG neurons might be supported by the larger periphery. Nonetheless, the critical issue is not the absolute numbers of DRG neurons in control slices but the percentage of neurons that remain after CNS ablation. These data demonstrated unequivocally that most E14 DRG neurons required the presence of the spinal cord and that this dependence is lost by approximately E16. Because previous studies were performed on postnatal animals (see introductory remarks), our results provide the first description of this early and transient dependence of DRG neurons on the CNS.

\section{REFERENCES}

Annis CM, Edmond J, Robertson RT (1990) A chemically defined medium for organotypic slice cultures. J Neurosci Methods 32:63-70.

Barber RP, Phelps PE, Vaughn JE (1993) Preganglionic autonomic motor neurons display normal translocation patterns in slice cultures of embryonic rat spinal cord. J Neurosci 13:4898-4907.

Burek MJ, Oppenheim RW (1996) Programmed cell death in the developing nervous system. Brain Pathol 6:427-446.

Calderó J, Prevette D, Mei X, Oakley RA, Li L, Milligan C, Houenou L, Burek M, Oppenheim RW (1998) Peripheral target regulation of the development and survival of spinal sensory and motor neurons in the chick embryo. J Neurosci 18:356-370.

Carr VM, Simpson Jr SB (1978a) Proliferative and degenerative events in the early development of chick dorsal root ganglia. I. Normal development. J Comp Neurol 182:727-740.

Carr VM, Simpson Jr SB (1978b) Proliferative and degenerative events in the early development of chick dorsal root ganglia. II. Responses to altered peripheral fields. J Comp Neurol 182:741-756.

Carr VM, Simpson Jr SB (1982) Rapid appearance of labeled degenerating cells in the dorsal root ganglia after exposure of chick embryos to tritiated thymidine. Dev Brain Res 2:157-162.

Chu-Wang IW, Oppenheim RW (1978) Cell death of motoneurons in the chick embryo spinal cord. II. A quantitative and qualitative analysis 
of degeneration in the ventral root, including evidence for axon outgrowth and limb innervation prior to cell death. J Comp Neurol 177:59-86.

Clarke PGH, Oppenheim RW (1995) Neuron death in vertebrate development: in vivo methods. Methods Cell Biol 46:277-321.

Coggeshall RE, Pover CM, Fitzgerald M (1994) Dorsal root ganglion cell death and surviving cell numbers in relation to the development of sensory innervation in the rat hindlimb. Dev Brain Res 82:193-212.

ElShamy WM, Ernfors P (1996) A local action of neurotrophin-3 prevents the death of proliferating sensory neuron precursor cells. Neuron 16:963-972.

Ernfors P, Persson H (1991) Developmentally regulated expression of HDNT/NT-3 mRNA in rat spinal cord motor neurons and expression of BDNF mRNA in embryonic dorsal root ganglion. Eur J Neurosci 3:953-961.

Ernfors P, Lee K-F, Kucera J, Jaenisch R (1994) Lack of neurotrophin-3 leads to deficiencies in the peripheral nervous system and loss of limb proprioceptive afferents. Cell 77:503-512.

Fariñas I, Jones KR, Backus C, Wang XY, Reichardt LF (1994) Severe sensory and sympathetic deficits in mice lacking neurotrophin-3. Nature 369:658-661.

Fariñas I, Yoshida CK, Backus C, Reichardt LF (1996) Lack of neurotrophin-3 results in death of spinal sensory neurons and premature differentiation of their precursors. Neuron 17:1065-1078.

Gavrieli Y, Sherman Y, Ben-Sasson SA (1992) Identification of programmed cell death in situ via specific labeling of nuclear DNA fragmentation. J Cell Biol 119:493-501.

Hamburger V, Levi-Montalcini R (1949) Proliferation, differentiation and degeneration in the spinal ganglia of the chick embryo under normal and experimental conditions. J Exp Zool 111:457-502.

Hamburger V, Yip JW (1984) Reduction of experimentally induced neuronal death in spinal ganglia of the chick embryo by nerve growth factor. J Neurosci 4:767-774.

Hamburger V, Brunso-Bechtold JK, Yip JW (1981) Neuronal death in the spinal ganglia of the chick embryo and its reduction by nerve growth factor. J Neurosci 1:60-71.

Himes BT, Tessler A (1989) Death of some dorsal root ganglion neurons and plasticity of others following sciatic nerve section in adult and neonatal rats. J Comp Neurol 284:215-230.

Hulsebosch CE, Coggeshall RE, Chung K (1986) Numbers of rat dorsal root axons and ganglion cells during postnatal development. Dev Brain Res 26:105-113.

Johnson Jr EM, Deckwerth TL (1993) Molecular mechanisms of developmental neuronal death. Annu Rev Neurosci 16:31-46.

Kitao Y, Robertson B, Kudo M, Grant G (1996) Neurogenesis of subpopulations of rat lumbar dorsal root ganglion neurons including neurons projecting to the dorsal column nuclei. J Comp Neurol 371:249-257.

Landmesser L, Pilar G (1976) Fate of ganglionic synapses and ganglion cell axons during normal and induced cell death. J Cell Biol 68:357-374.

Lawson SN, Caddy KWT, Biscoe TJ (1974) Development of rat dorsal root ganglion neurones. Studies of cell birthdays and changes in mean cell diameter. Cell Tissue Res 153:399-413.

Liebl DJ, Tessarollo L, Palko ME, Parada LF (1997) Absence of sensory neurons before target innervation in brain-derived neurotrophic factor-, neurotrophin 3-, and TrkC-deficient embryonic mice. J Neurosci 17:9113-9121.

McConkey DJ, Orrenius S (1994) Signal transduction pathways to apoptosis. Trends Cell Biol 4:370-375.

McLean IW, Nakane PK (1974) Periodate-lysine-paraformaldehyde fixative. A new fixative for immunoelectron microscopy. J Histochem Cytochem 22:1077-1083.

Migheli A, Cavalla P, Marino S, Schiffer D (1994) A study of apoptosis in normal and pathologic nervous tissue after in situ end-labeling of DNA strand breaks. J Neuropathol Exp Neurol 53:606-616.

Mirnics K, Koerber HR (1995) Prenatal development of rat primary afferent fibers. II. Central projections. J Comp Neurol 355:601-614.

Oakley RA, Lefcort FB, Clary DO, Reichardt LF, Prevette D, Oppenheim RW, Frank E (1997) Neurotrophin-3 promotes the differentiation of muscle spindle afferents in the absence of peripheral targets. J Neurosci 17:4262-4274.

Oppenheim RW (1991) Cell death during development of the nervous system. Annu Rev Neurosci 14:453-501.

Ozaki S, Snider WD (1997) Initial trajectories of sensory axons toward laminar targets in the developing mouse spinal cord. J Comp Neurol 380:215-229.

Phelps PE, Barber RP, Vaughn JE (1996) Nonradial migration of interneurons can be experimentally altered in spinal cord slice cultures. Development 122:2013-2022.

Qin-Wei Y, Johnson J, Prevette D, Oppenheim RW (1994) Cell death of spinal motoneurons in the chick embryo following deafferentation: rescue effects of tissue extracts, soluble proteins, and neurotrophic agents. J Neurosci 14:7629-7640.

Riethmacher D, Sonnenberg-Riethmacher E, Brinkmann V, Yamaai T, Lewin GR, Birchmeier C (1997) Severe neuropathies in mice with targeted mutations in the ErbB3 receptor. Nature 389:725-730.

Robertson RT, Annis CM, Gähwiler BH (1989) Production of organotypic slice cultures of neural tissue using the roller-tube technique. In: Cellular and molecular neurobiology: a practical approach (Wheal $\mathrm{H}$, Chad J, eds), pp 39-56. Oxford: IRL.

Rossiter JP, Riopelle RJ, Bisby MA (1996) Axotomy-induced apoptotic cell death of neonatal rat facial motoneurons: time course analysis and relation to NADPH-diaphorase activity. Exp Neurol 138:33-44.

Ruit KG, Elliott JL, Osborne PA, Yan Q, Snider WD (1992) Selective dependence of mammalian dorsal root ganglion neurons on nerve growth factor during embryonic development. Neuron 8:573-587.

Scaravilli F, Duchen LW (1980) Electron microscopic and quantitative studies of cell necrosis in developing sensory ganglia in normal and Sprawling mutant mice. J Neurocytol 9:373-380.

Schecterson LC, Bothwell M (1992) Novel roles for neurotrophins are suggested by BDNF and NT-3 mRNA expression in developing neurons. Neuron 9:449-463.

Sims TJ, Vaughn JE (1979) The generation of neurons involved in an early reflex pathway of embryonic mouse spinal cord. J Comp Neurol 183:707-720.

Smale G, Nichols NR, Brady DR, Finch CE, Horton Jr WE (1995) Evidence for apoptotic cell death in Alzheimer's disease. Exp Neurol 133:225-230.

Snider WD (1994) Functions of the neurotrophins during nervous system development: what the knockouts are teaching us. Cell 77:627-638.

Snider WD, Wright DE (1996) Neurotrophins cause a new sensation. Neuron 16:229-232.

Snider WD, Zhang L, Yusoof S, Gorukanti N, Tsering C (1992) Interactions between dorsal root axons and their target motor neurons in developing mammalian spinal cord. J Neurosci 12:3494-3508.

Tessarollo L, Vogel KS, Palko ME, Reid SW, Parada LF (1994) Targeted mutation in the neurotrophin-3 gene results in loss of muscle sensory neurons. Proc Natl Acad Sci USA 91:11844-11848.

Vaughn JE, Phelps PE, Yamamoto M, Barber RP (1992) Association interneurons of embryonic rat spinal cord transiently express the cell surface glycoprotein SNAP/TAG-1. Dev Dyn 194:43-51.

Wetts R, Vaughn JE (1993) Transient expression of $\beta$-NADPH diaphorase in developing rat dorsal root ganglia neurons. Dev Brain Res 76:278-282.

Wetts R, Vaughn JE (1996) Differential vulnerability of two subsets of spinal motor neurons in amyotropic lateral sclerosis. Exp Neurol 141:248-255.

Wetts R, Vaughn JE (1998) Differences in developmental cell death between somatic and autonomic motor neurons of rat spinal cord. J Comp Neurol 396:483-492.

Wetts R, Phelps PE, Vaughn JE (1995) Transient and continuous expression of NADPH diaphorase in different neuronal populations of developing rat spinal cord. Dev Dyn 202:215-228.

White FA, Silos-Santiago I, Molliver DC, Nishimura M, Phillips H, Barbacid M, Snider WD (1996) Synchronous onset of NGF and TrkA survival dependence in developing dorsal root ganglia. J Neurosci 16:4662-4672.

White FA, Keller-Peck CR, Knudson CM, Korsmeyer SJ, Snider WD (1998) Widespread elimination of naturally occurring neuronal death in Bax-deficient mice. J Neurosci 18:1428-1439.

Wright DE, Zhou L, Kucera J, Snider WD (1997) Introduction of a neurotrophin-3 transgene into muscle selectively rescues proprioceptive neurons in mice lacking endogenous neurotrophin-3. Neuron 19:503-517.

Yip HK, Johnson Jr EM (1984) Developing dorsal root ganglion neurons require trophic support from their central processes: evidence for a role of retrogradely transported nerve growth factor from the central nervous system to the periphery. Proc Natl Acad Sci USA 81:62456249. 